\title{
Solitary Sternal Plasmacytoma: A Case Report And Current Review
}

\author{
I Dimarakis, J Thorpe, K Papagiannopoulos
}

\begin{abstract}
Citation
I Dimarakis, J Thorpe, K Papagiannopoulos. Solitary Sternal Plasmacytoma: A Case Report And Current Review. The Internet Journal of Thoracic and Cardiovascular Surgery. 2004 Volume 7 Number 1.
\end{abstract}

DOI: $\underline{10.5580 / 1932}$

\begin{abstract}
A 74-year-old male presented with localised lower sternal discomfort. Initially investigated for ischaemic heart disease, the patient was finally diagnosed with a sternal tumour. He subsequently underwent primary surgical excision and histopathological findings were consistent with a solitary plasmacytoma. We discuss the difficulty in diagnosing solitary plasmacytomas, as they may be subtle presentations of multiple myeloma. Therapeutic challenges also exist with radiotherapy and surgery alone or in combination offering good results.
\end{abstract}

\section{INTRODUCTION}

Solitary plasmacytoma of bone is a rare osseous malignancy that does present ever so often to the general thoracic surgeon. Occurring mostly in the bones of the axial skeleton it represents a small percentage of plasma cell tumours. The natural progress of the disease has been well documented with most patients progressing to multiple myeloma; a few patients may develop solitary recurrences in bone or even a local recurrence. The disease free survival is about 40 per cent at 5 years and 15 to 30 per cent at 10 years $\left({ }_{1},{ }_{2}\right)$.

\section{CASE REPORT}

A 74-year-old gentleman presented to his general practitioner with localised discomfort over the lower end of his sternum. A possible diagnosis of angina pectoris was considered based on the characteristics of his symptoms along with a degree of lateral ST abnormalities noticed on his electrocardiogram. The patient was commenced on first line treatment for stable angina and referred for further evaluation to a cardiology clinic.

No symptomatic change was observed with initiation of antianginal medication and no criteria were met to either continue with these or even proceed with an exercise test. Routine laboratory tests were normal and his echocardiogram showed no evidence of left ventricular hypertrophy.
During the initial workup a chest $\mathrm{x}$-ray had been requested. Signs of bone expansion involving the lower body of the sternum on the lateral view were seen (Fig1A). Magnetic resonance imaging of the patient's anterior chest wall confirmed the presence of a 4 × $3 \times 3 \mathrm{~cm}$ soft tissue mass involving the lower sternum and xiphisternum. This was extending into the overlying musculature and adjacent costal cartilages. The above features were consistent with a sternal tumour (Fig1B).

\section{Figure 1}

Figure 1: A. Lateral chest film showing the sternal tumour. B. Magnetic resonance imaging revealing full extent of mass.
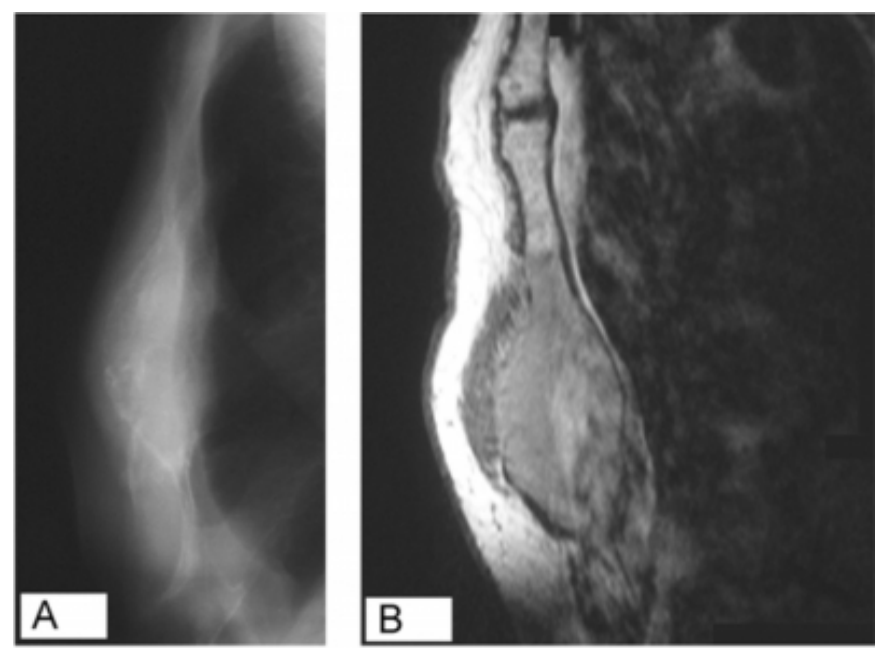
The patient was referred to the general thoracic surgical clinic for further management. Although the clinical and radiological features were highly suggestive of a primary malignancy a whole body computed tomography scan was organised to exclude any metastatic origin. This did not demonstrate any pathology.

Operative treatment was decided and a partial sternectomy along with anterior chest wall reconstruction was undertaken. The tumour was excised with almost $60 \%$ of the sternum as well as four pairs of cartilages (Fig2). The subsequent defect was reconstructed with a 'sandwich' of marlex mesh re-enforced with biological cement.

\section{Figure 2}

Figure 2: Intra-operative picture during primary excision.

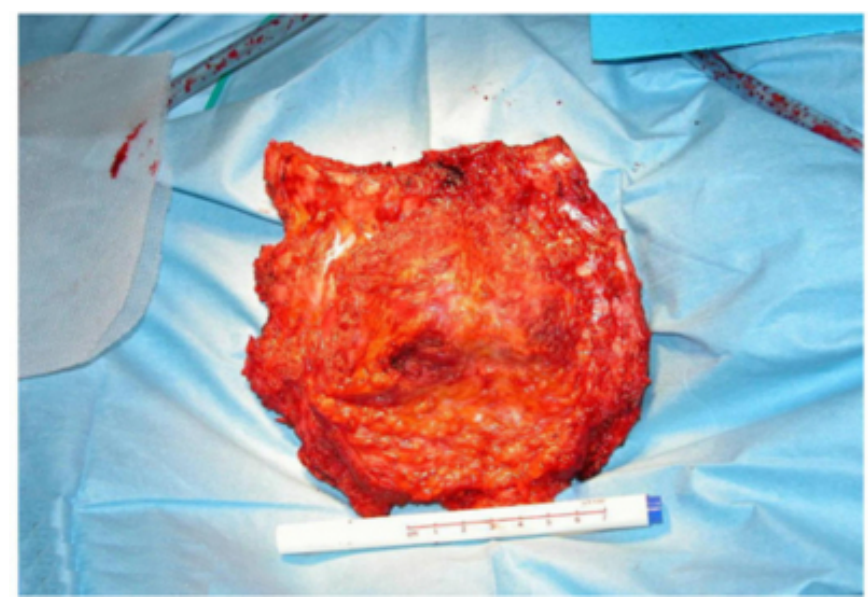

On histopathological examination a large central tumour was present eroding from the internal to external surface of the sternum. This was composed of relatively monomorphic small plasma cells with a high nuclear cytoplasmic ratio. The appearances were those of a plasmacytoma (Fig3).

\section{Figure 3}

Figure 3: Microscopic features of the resected specimen confirming the diagnosis of plasmacytoma (stain: haematoxylin\&ndash;eosin, magnification: 10 microns on long axis).

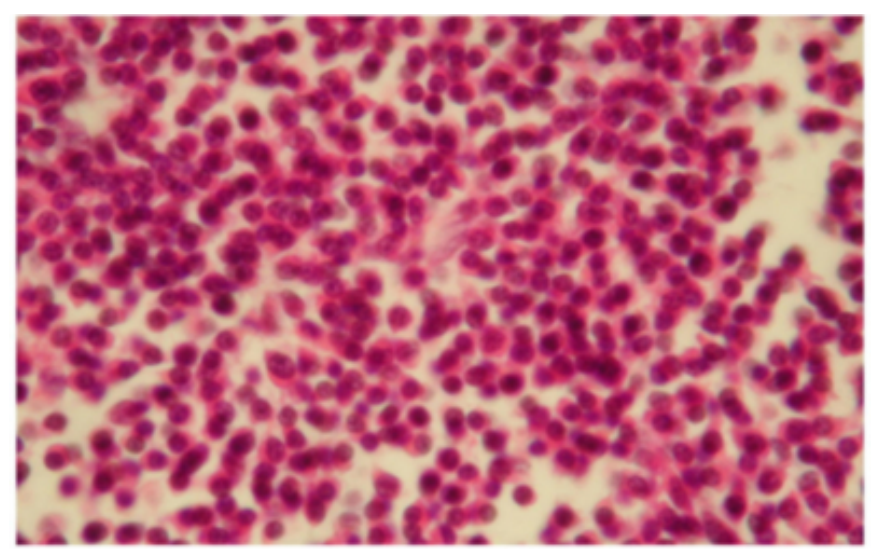

The patient developed atrial fibrillation but otherwise made an uncomplicated post-operative recovery. Further investigations revealed a monoclonal gammopathy of uncertain significance solidifying the diagnosis of solitary plasmacytoma. Post-operative radiotherapy was not deemed necessary. The patient remains well after six months under regular follow-up in the haematology and thoracic clinic.

\section{DISCUSSION}

Solitary plasmacytomas of bone are defined as clonal proliferations of plasma cells identical to those of plasma cell myeloma, which manifest a localised osseous growth. The most common sites are in marrow areas of most active haemopoiesis such as the vertebral column. Rib and sternal involvement accounts for $10-15 \%$ of cases. Solitary plasmacytoma is twice as frequent in males with a median age of presentation 55 years. That is nearly ten years earlier than patients presenting with myeloma. The most common presentation is pain at the site of the bone lesion $\left({ }_{1}, 2\right)$.

It is well recognised that from an imaging point of view initial staging of a solitary plasmacytoma is a challenge. Conventional x-ray skeletal survey and bone scintigraphy have both been shown to understage the disease in a significant percentage of patients. MRI of the spine has shown to exclude additional lesions $\left(_{3}\right)$. Recent studies have compared the above modalities with $99 \mathrm{mTc}$-MIBI scintigraphy in order to increase diagnostic sensitivity $\left(_{4}\right)$. Even more promising initial results have been published regarding the assessment of solitary plasmacytoma with fluorine-18 fluorodeoxyglucose positron emission tomography ${ }_{5}$ ). 
In our institution all primary sternal tumours are considered malignant until a final tissue diagnosis is obtained. The surgical method of obtaining histopathologic confirmation is determined mainly by the size of the tumour. Excisional biopsy is carried out with any tumour less then $4 \mathrm{~cm}$. Incisional biopsy is the preferred approach to any lesion greater then $4 \mathrm{~cm}$, providing the biopsy site is excised at the time of definitive surgery ${ }_{6}{ }_{6}$.

Patients with a solitary plasmacytoma of the sternum diagnosed on incisional biopsy are further investigated to exclude the presence of multiple myeloma. Complete skeletal survey must show no other lesions, and the bone marrow away from the solitary lesion no evidence of plasmacytosis $>5 \%$. There must be no signs of systemic disease. Routine haematology and biochemistry investigations are carried out along with immunoelectrophoresis, immunofixation and immunoglobulin quantitations of serum and urine concentrates. These patients are referred for definitive local radiotherapy $\left(_{3}\right)$.

In those patients in whom the dimensions of the tumour are less than $4 \mathrm{~cm}$ routine haematology and biochemistry tests along with a whole body computed tomography examination are performed. If no contraindications are present a complete surgical resection and primary reconstruction is undertaken. If the histopathologist suggests a plasma cell tumour diagnosis the patient is investigated as above. Complete excision is thought to be curative $\left({ }_{7}, 8\right)$, but supplemental local radiotherapy may be considered depending on the histopathology and further staging $\left({ }_{9}\right)$. Optimum patient selection is crucial in both groups as certain patients have a high likelihood of cure.

The most important factor that limits the long-term survival of these patients is the development of multiple myeloma $\left(_{2}\right)$. Routine clinical examination and laboratory screening is mandatory to detect local or systemic recurrences.

\section{CORRESPONDENCE TO}

Mr Ioannis Dimarakis MRCS Department of Surgical Oncology \& Technology Imperial College Faculty of Medicine Hammersmith Hospital Campus London, W12 ONN, United Kingdom ioannis.dimarakis@imperial.ac.uk

\section{References}

1. Grogan T, Van Camp B, Kyle R, Muller-Hermelink H, Harris N. Plasma cell neoplasms. In: Jaffe E, Harris N, Vardiman J, editors. World Health Organization Classification of Tumours. Pathology and Genetics of Tumours of Haematopoietic and Lymphoid Tissues. Lyon: IARC Press; 2001.

2. Morgan G, Selby P. Myeloma. In: Souhami R, Tannock I, Hohenberger P, Horiot J-C, editors. Oxford Textbook of Oncology. 2 ed. New York: Oxford University Press; 2002. p. 2419-2455.

3. Liebross RH, Ha CS, Cox JD, Weber D, Delasalle K, Alexanian R. Solitary bone plasmacytoma: outcome and prognostic factors following radiotherapy. Int J Radiat Oncol Biol Phys 1998;41:1063-7.

4. Alper E, Gurel M, Evrensel T, Ozkocaman V, Akbunar T, Demiray M. 99mTc-MIBI scintigraphy in untreated stage III multiple myeloma: comparison with X-ray skeletal survey and bone scintigraphy. Nucl Med Commun 2003;24(5):537-42.

5. Schirrmeister H, Buck AK, Bergmann L, Reske SN, Bommer M. Positron emission tomography (PET) for staging of solitary plasmacytoma. Cancer Biother Radiopharm 2003;18(5):841-5.

6. Sabanathan S, Shah R, Mearns AJ. Surgical treatment of primary malignant chest wall tumours. Eur J Cardiothorac Surg 1997;11(6):1011-6.

7. Pezzella AT, Fall SM, Pauling FW, Sadler TR. Solitary plasmacytoma of the sternum: surgical resection with longterm follow-up. Ann Thorac Surg 1989;48(6):859-62.

8. Wilkinson S, Forrester-Wood CP. Surgical resection of a solitary plasmacytoma originating in a rib of a patient with Castleman's disease. Ann Thorac Surg 2003; 75:1018-1019. 9. Liptay M, Fry WA. Malignant bone tumors of the chest wall. Semin Thorac Cardiovac Surg 1999;11:278-84. 


\section{Author Information}

Ioannis Dimarakis, MRCS

Department of Thoracic Surgery, Leeds General Infirmary

\section{James AC Thorpe, FRCS}

Department of Thoracic Surgery, Leeds General Infirmary

Kostas Papagiannopoulos, MMED

Department of Thoracic Surgery, Leeds General Infirmary 